\title{
Report
}

\section{Cultivation of Cultural Empathy Competence from the Perspective of Intercultural Communication}

\author{
Li Yujie \\ College of Teacher Education, Nanjing Normal University, Nanjing, China
}

Email address:

Jasperlyj@163.com

\section{To cite this article:}

Li Yujie. Cultivation of Cultural Empathy Competence from the Perspective of Intercultural Communication. International Journal of Secondary Education. Vol. 7, No. 2, 2019, pp. 29-32. doi: 10.11648/j.ijsedu.20190702.11

Received: March 14, 2019; Accepted: April 15, 2019; Published: May 15, 2019

\begin{abstract}
The focus of current foreign language teaching is to cultivate students' cultural awareness. The ultimate goal of foreign language teaching is to cultivate students' intercultural communicative competence, and cultural empathy competence is the most important factor in the intercultural communicative competence system, which will directly affect the quality, effect and process of intercultural communication. In the process of intercultural communication, people begin to realize that the cultural empathy competence is the most important part of the intercultural communication system, which will directly affect the quality, effect and process of intercultural communication. In English teaching, the education and training of cultural empathy competence is an indispensable part in cultivating students' comprehensive English competence. Reaching the ideal state of empathy is not an overnight process, but a long process of psychological adaptation and behavioral identification, which determines the nature of difficulty and long-term of cultural empathy. Therefore, in English teaching, teachers should not only teach language knowledge, but also impart cultural knowledge, guide students to realize the differences and similarities between Chinese and western cultures, cultivate students' intercultural communication awareness through multiple ways, and skillfully guide students to carry out cultural empathy, so as to improve the effect of English teaching.
\end{abstract}

Keywords: Cultural Empathy Competence, Intercultural Communication, English Teaching

\section{Introduction}

With the development of the world's diversification and the steady implementation of the "The Belt and Road" initiative, the conflicts and integration between different cultures have become more and more obvious. Intercultural communication has become an essential part of today's life. In 1972, Hymes first put forward the concept of communicative competence. [1] Since then, intercultural communication has become a hot topic for scholars at home and abroad. At present, the cultivation of intercultural communicative competence has been regarded as the ultimate goal of foreign language teaching in China. Many domestic well-known scholars have carried out effective research work in this field. They have effectively solved the problem of how to teach and what to teach in the actual teaching process, and pay attention to the construction of the concept of cultural difference and the practical communicative competence of learners in the learning process. The attention paid by domestic and foreign academia to the cultural empathy competence indicates that the study of intercultural communication has developed from surface study to deep study.

\section{The Importance of Cultural Empathy Competence in Intercultural Communication}

\subsection{Concept of Cultural Empathy Competence}

The concept of "empathy" first comes from western aesthetics, which means that the subject imparts its spirit and emotion to the objective object, and makes the image load and thematic feelings of objective external objects become the emotional expression of the subject's experience. From the perspective of psychology, empathy is to produce an emotional experience close to the feelings of others through the perception 
of emotions, which is equivalent to emotional resonance. Ziran He (1991) first put forward the concept of empathy in the domestic academia. Humanistic language learners should understand and feel the culture of the target language country, and learn and apply the language in its cultural background.

\subsection{The Cultural Empathy Competence Is the Core of Intercultural Communicative Competence}

Intercultural communicative competence is a comprehensive competence, which is manifested in a system with rich contents and complex and diverse elements. Ruben believes that the concept of intercultural communicative competence is the competence to have the same unique activities as individuals in a certain environment to achieve their personalities, goals and expectations. [2] It's a relative competence to meet people's basic requirements, satisfy their personalities, and achieve their goals and expectations. He divides intercultural communicative competence into seven elements: First, the competence to show respect and a positive attitude towards the target communicator; Second, the competence to adopt descriptive, non-evaluative and non-judgmental attitudes; Third, the competence to understand each other's personality to the maximum; Fourth, empathy competence; Fifth, the flexible competence to cope with different situations; Sixth, the mutual communication competence of taking turns to talk; Seventh, the competence to tolerate new and ambiguous situations and to respond to them with ease. If we carry out item-to-item interpretation, we can find that Ruben's seven effective elements were that communicators should try to communicate with other cultures taken into account. In this sense, the communicative process under Ruben's seven effective elements was actually a communicative process under empathy. Cultural empathy competence is the key factor affecting the success of intercultural communication.

The cultural empathy competence is the most prominent feature in the intercultural communication system, which is the primary premise and fundamental guarantee of cultural communication. Every social group has its own cultural background. Due to the differences in social system, national tradition, geographical environment, values and lifestyles, people with different cultural backgrounds have distinctive language, cultural and communication modes, which are often incompatible. Thus, cultural empathy is necessary for successful communication among people from different cultural backgrounds. [3] Therefore, for English teaching, the education and training of learners' cultural empathy competence is an important part of cultivating students' intercultural communicative competence.

\section{The Main Ways and Methods of Cultivating the Cultural Empathy Competence in Intercultural Communication}

The cultural empathy competence needs to be cultivated and trained gradually. Therefore, in English teaching, teachers should pay attention to the transmission of cultural knowledge and the construction of intercultural awareness while imparting language knowledge. There are three ways to cultivate students' cultural empathy competence:

\subsection{Learn Natural and Authentic Language Expressions by Appreciating and Analyzing Literary Works}

Reading works of the target language is an important way to learn foreign cultural knowledge. The literary works of a nation are the essence of its culture and the accumulation of its traditional culture. This is an endless source of language for learners. Teachers can guide students to carefully analyze the historical background and main characters or events of literary works, on the basis of mastering language knowledge and understanding the text. [4] Thus, students can accurately grasp the content of the works, broaden their horizons, improve their literacy, consciously understand western culture, compare the differences between Chinese and western culture, and develop their own analytical and accepting ability. In addition, watching original English movies and TV programs can expose students to the language, thinking, customs, culture and social life of western world. By watching these films and TV programs, students can have a more direct understanding of the lifestyles, social and cultural customs, interests, way of thinking and values of English-speaking countries, so as to cultivate students' intercultural awareness in practical communication and enhance their intercultural communicative competence. By using multimedia to project film and television works, teachers should pay attention to guiding students to observe the society, culture and other aspects of English-speaking countries in detail. [5]

\subsection{Impart Cultural Knowledge in Teaching and Guide Students to Make Cultural Comparison}

In English teaching, teachers should teach students the law of cultural relativity, constantly increase the introduction and teaching of cultural background knowledge, and pay attention to the three principles of cultural introduction: the principle of practicability, stage and suitability. [6] Only by comparing and finding the similarities and differences between students' mother tongue and target language in language structure and culture can the students acquire a kind of cultural sensitivity of intercultural communication. For example, in Britain, the United States and some other countries, people generally wear black funeral dress to express solemnity and mourning for the dead; while in China, people often wear white. This kind of comparative observation of culture is beneficial for students to experience and feel the culture of English-speaking countries, eliminate the prejudice of national cultural differences, and thus achieve language and emotional communication. To cultivate students' intercultural awareness, teachers should start from listening, speaking, reading and writing in teaching. [7] In daily life, pleasantries, greetings, thanks, wishes, apologies, comity, euphemism and taboos all have certain fixed patterns restricted by national culture. For example, 
Chinese people often use noncommittal or ambiguous words to say "no" in daily communication, because our communication mode believes that refusing an invitation or request from a friend will often lead to the breakdown of friendship. Therefore, the Chinese would rather promise than refuse outright. But for British and American culture, this means breaking the promise and reneging on the obligations undertaken. With these backgrounds mastered, students can stand in the other side of position, understand the other's speech intention and grasp the semantic connotation of the text in the process of language input learning. Only when students consciously carry out cultural empathy, surpass the fetters of native culture mentally and emotionally, and become a person with multi-cultural connotation, can they reduce cultural friction and adapt to the needs of social development. [8]

\subsection{Make Full Use of Extracurricular Time to Enhance the Practice of Language Knowledge and Cultural Knowledge}

English teaching can transcend the limitations of classroom teaching and provide learners with a variety of language learning environments. Communicative competence is not only the simple sum of linguistic competence and cultural competence, but also the result of a great deal of practice. [9] Practice is the main way to acquire cultural knowledge and carry out cultural empathy. In English teaching, various methods can be adopted to carry out cultural teaching, so as to cultivate students' cultural awareness and facilitate learners' cultural empathy. For example: carry out relevant English competition activities -- holding English speech, English drama, English essay; carry out cultural activities -- watching relevant English documentaries or cultural films, learning to sing English songs, holding English evening parties, celebrating foreign language festivals; News media -- opening English radio programs, making English hand-written newspapers and blackboard newspapers; Organize English salons, debates and special lectures to immerse students in the cultural environment of the target language. [10] Cultural lectures can reintegrate fragmented cultural information. It's an effective teaching strategy that systematically illustrates a holistic concept, while providing students with the latest research findings. And social participation, such as organizing English corner activities, inviting foreign teachers to guide and teach, meetings with foreign friends, making pen friends, enable students to practice the language in various forms, consolidate and improve it, feel the foreign cultural atmosphere, stay in the life of foreign culture, and improve their cultural adaptability. [11]

\section{Conclusion}

Reaching the ideal state of empathy is not an overnight process, but a long process of psychological adaptation and behavioral identification, which determines the nature of difficulty and long-term of cultural empathy. [12] But as long as the teachers guide students to treat cultural differences objectively and dialectically, analyze the cultural factors calmly, change their perspective to understand and respect the existing cultural differences, while upholding and carrying forward the national culture, enhancing tolerance and absorption of western culture in seeking common ground gradually, while putting aside differences, can they cultivate inter-disciplinary talents to meet the needs of the time and conduct intercultural communication. [13] When teachers focus on cultivating learners' awareness of cultural differences, however, they cannot just emphasize the differences between cultures and ignore the fundamental differences in social backgrounds. Therefore, teachers must also pay attention to things common to all human beings. They can focus on explaining different reasons while attaching importance to the consistency of ontology. [14] Our purpose is to cultivate students to be intercultural communication talents with good ideological and moral quality, cultural quality and psychological quality. [15] This means in intercultural communication, students should not only have the ability to understand other cultures, but also have the awareness of cultural empathy, so that they can correctly understand each other and express themselves without losing themselves because of excessive empathy, and become mature language learners who have emotional awareness but won't lose themselves.

\section{References}

[1] Gu Jiazu. Cross-cultural Communication: Hidden Culture in Foreign Language and Literature [M]. Nanjing: Nanjing Normal University Press, 2000.

[2] Jia Yuxin. Intercultural Communication [M]. Shanghai: Shanghai foreign Language Education Press, 1997.

[3] Chen Xijie. Compliance with the Principle of Pragmatic Cooperation and Cultivation of Cultural Empathy in Cross-cultural Communication [J]. Journal of Inner Mongolia Normal University (Educational Science), 2011, 24(11):116-120.

[4] Shan Min. Cultural Empathy of Communicators in Cross-cultural Context [J]. Jiangxi Social Science, 2013, 33(03):229-232.

[5] Lu Zongli, Liu Xia. Cultivation of English Learners' Cultural Empathy Ability from the Perspective of Second Language Acquisition [J]. Overseas English, 2018(07):16-17.

[6] Yue Manman. College English Teaching from the Perspective of Transforming Empathy $[\mathrm{J}]$. Overseas English, 2016(09):57-58.

[7] Yu Kun. Cultivation of Cultural Empathy Ability of College Students in Cross-cultural Teaching [J]. Journal of Jiamusi Vocational Institute, 2018(06):161-162.

[8] Xu Zhiqi. Cultivation of intercultural communicative competence under the background of "one belt and one road" [J]. Literature Education, 2018(07):105.

[9] Zhu Xiaoli. Framework Construction of Cross-cultural Communicative Competence Training in Second Foreign Language Teaching [J]. Journal of Neijiang Normal University, 2019(03):95-99. 
[10] Zheng Juejun, Cultivation of Intercultural Awareness of English Majors [J]. China Journal of Multimedia \& Network Teaching, 2019(03):223-224.

[11] Peng Bingzhuan. A Study on the Cultural Transmission of English Films and the Cultivation of Students'Intercultural Communicative Competence [J]. Heilongjiang Education (Theory \& Practice), 2019(Z1):87-88.

[12] Dou Wenna. Teaching Reform of General Education Core Course in Colleges and Universities under the Concept of Cross-cultural Ability Training [J]. Education Teaching Forum, 2019(13):77-79.
[13] Wang Shuang. A Study on the Cultivation of Cross-cultural Communicative Competence under the Background of Cultural "Going Out" [J]. Science \& Technology Vision, 2018(29):71-73.

[14] Gao Yuanyuan, On the Cultivation of Intercultural Communicative Competence [J]. Course Education Research, 2018(45):51.

[15] Hou Songzhu. The Cultivation of Intercultural Communicative Competence and the Study of Educational Psychology [J]. Education Modernization, 2018, 5(47):369-370. 